\title{
Social minds
}

\author{
Mentes sociais
}

Sofia Inês Albornoz Stein*

\begin{abstract}
One of the key questions of the philosophy of mind is that of other minds. The problem consists in questioning whether it is possible to achieve a state of reliable knowledge about what other persons feel, think, and intend. This was one of the central questions of modern philosophy, first raised by Renée Descartes. ${ }^{1}$ Initially, his response to this question was a skeptic one: there is no ultimate guarantee for our affirmations concerning the content, states and mental processes of other minds. Indeed, modern skepticism goes even further: we have no guarantee for what we believe happens in the exterior world, and therefore not even the content of our own thoughts is reliable. We can infer from the fact that we are sometimes misled by our own senses that we may always be wrong about what the objects in the world really are, and about what actually happens in the world. Our own body and the bodies and minds of other persons are part of something we have doubtful knowledge of, since this knowledge must be filtered by our own limited sensory capacities.
\end{abstract}

As of the mid-20th century, a new interpretation of this key question was put forward by philosophers of the pragmatic tradition, such as Ludwig Wittgenstein (Philosophical Investigations, 19532), Gilbert Ryle (The Concept of Mind, 19493) and John Austin (Other Minds, $1946^{4}$ ). The starting point for trying to answer the key question posed is no longer an introspective reflection on our capacity for knowing the world, our own body, and the bodies and minds of others, but rather stems from common sense and ordinary belief. The mistakes, illusions, and hallucinations that form part of our many (largely successful) attempts to know the world do not present a threat to the ordinary belief contained within our cognitive capacities.
In the same context, Willard Quine (Epistemology Naturalized, 19695) asserts that we do not need to avoid the circularity that is inherent to our investigations concerning how we know something, i.e., the physical and mental capacities that provide us with knowledge, and whose workings we strive to explain, are the same ones we use to carry out our investigations. Thus, when we seek a guarantee for scientific knowledge, what we encounter is guarantees that can only be arrived at by means of that very same knowledge, and therefore the circularity of the process of justification is inevitable. We can create methods and instruments that will help us to move forward in our investigations, however to the limits of our cognitive capacities. The certainties that we arrive at are always partial, and are the result of using methods and tools that allow us to go beyond the established boundaries of our innate capacity for investigation.

Modern skepticism is still deeply rooted in contemporary thought, and we still have theoretical doubts about our capacity to know the world and other minds. Language is an essential part of our resources for thinking about how we can overcome skepticism and know other minds. As advanced science helps us to explain, minds are partly products of socially acquired linguistic structures. We are born with cognitive mental dispositions, some of which allow us to verbalize cognitive content.

An important contribution to our reflection on the relationship between cognitive content, some of it originating from the senses, and our verbalization of this content was made by Wittgenstein in his later work. Indeed, many other philosophers still share a view that is very close to his. What they all basically maintain is that, on the one hand, common sense is correct in affirming

* PhD. Professor, Universidade do Vale do Rio dos Sinos (UNISINOS), São Leopoldo, RS, Brazil. Investigator, Programa de Pós-Graduação em Filosofia, Conselho Nacional de Desenvolvimento Científico e Tecnológico (CNPq), and Grupo de Pesquisa Social-Brains (http://welcome.to/socialbrains). E-mail: siastein@gmail.com No conflicts of interest declared concerning the publication of this editorial.

Suggested citation: Stein SI. Social minds. Trends Psychiatry Psychother. 2012;34(4):167-70 
that we can know what other persons are thinking by observing their corporeal and verbal behavior. On the other hand, however, common sense is wrong about the possibility of being able to exactly identify the mental states of others. We often suppose that we know what other persons are feeling, perceiving, desiring, thinking, and intending, and we are able to verbalize this supposition, to the extent that it is approximately, but not totally, correct. Why is this the case? The philosophical justification for the impossibility of exactly identifying the mental states of others, which is part of Wittgenstein's argument against private language, goes as follows: the language we use to talk about our own mental states and those of others is public, not private. Its fundamental aim is to communicate what we feel, perceive, think, and intend. However, our use of the terms feel, perceive, think, and intend is a result of a public practice, and this shows that we only know how to refer to our internal states once we have learnt how to use these terms publically. From this we can infer that there is a certain indeterminacy in the references we make to our own mental states and to those of others. This is because the language we use to describe these states is, and possibly always will be, common psychological language (Folk Psychology), with no scientific foundation, and it does not identify mental or physicochemical objects that can be individualized. This is one of the main conclusions of the philosophy of mind, which takes into account the teachings of Wittgenstein.

There is, therefore, a gap between common, natural, ordinary language and scientific language. This gap first manifests itself when we analyze ordinary discourse concerning mental content, mental states, and mental processes. This discourse is rooted in socially acquired language with practical aims that do not require an exact reference to mental objects or to corporeal or cerebral processes. However, as part of our social practices, we are still able to successfully express our desires, thoughts, and intentions in this ordinary language, even though it is not exact. The gap between this way of describing the mind and more scientific descriptions is one of the greatest difficulties we face in current reflections on the human mind.

If, for the moment, we ignore this gap (whose existence we acknowledge, even though we are not sure it will ever be eliminated), we continue to be concerned about "reading other minds" in a scientific way. Our intention is not only to measure, quantify and visualize the mind by means of electroencephalography (EEG) or magnetic resonance imaging (MRI) examinations, but also to describe mental phenomena as they occur. The language that psychological researchers use to describe such phenomena is still, in many ways, the common language of Folk Psychology, even though a large amount of specialized vocabulary has been added to this core.

As described in an article published in this issue of Trends in Psychiatry and Psychotherapy, SanvicenteVieira, Brietzke, and Grassi-Oliveira have coordinated the translation of two tests entitled Theory of Mind Stories and Hinting Task, designed to identify reductions in the social cognition capacity of patients with schizophrenia. ${ }^{6}$ The fundamental presupposition of these tests, originally designed by Frith \& Corcoran and revised by Moore et al., is that certain psychopathologies, such as schizophrenia, are accompanied by a reduction in social functionality. The authors believe that the translation and subsequent use of these tests in Brazil will make it possible, in addition to arriving at a better understanding of the pathologies and their symptoms, to reflect on how to improve the capacity of schizophrenic patients to function socially by clinical means. Another presupposition central to the authors' approach is that these tests will allow them to reach important conclusions concerning which mental capacities used in social relationships are reduced in patients with psychopathologies.

The tests are not primarily considered as a means to diagnose psychopathologies (even partially), although they could be used for such purpose in the future. Thus, there is a circularity in the preparation of these tests that is, at bottom, inherent to all empirical tests: it is presupposed that there is a specific type of reduction of cognitive capacity, and tests are created to identify this performance deficit. As a result, the tests do not identify new cognitive reductions over and above those already presupposed as being possible among the patients submitted to the tests.

One of these tests, the Hinting Task, presupposes that, in social relationships, it is necessary to arrive at correct conclusions concerning the intentions of third parties. In all tests, the main factor assessed is how the interviewees behave when they are questioned, and how they need to reflect on (or read the minds of) certain characters in stories told by the interviewers. It is expected that the person being interviewed will be able to imagine the situations in the story being told, and that (s)he will be able to say what the various characters think, believe, and intend, whilst taking into account their verbal and non-verbal actions. Thus, what (s)he does is to respond, based on descriptions of verbal or non-verbal behavior, to something that should supposedly have been acquired socially concerning what happens in other minds when certain individuals behave in a particular way. We can see that what is required here is the use of capacities that clearly do not involve direct mind-reading, or direct deductions concerning what other persons think based on what they say, but 
rather inferences about what others think and intend based on a determined context and on what they say in this context.

The second test whose translation was coordinated by the authors is entitled Theory of Mind Stories, or ToM Stories, a series of classic tasks that deal with the idea of false beliefs. The purpose of this test is to assess the individual's capacity to infer (to arrive at a first-order belief about) how a subject A will behave when (s) he does not know a determined fact, or holds a false belief about this fact. Alternatively, the test can assess the individual's capacity to infer (to arrive at a secondorder belief about) how a subject B will behave when (s) he knows of the ignorance or false belief of subject $A$. In addition to coordinating the translation of the tests, the authors also ran a pilot study with four Brazilian volunteers. The next step will be to apply the tests to clinical patients.

Theories of mind are, in a figurative sense, readings of the mind. In social terms, we learn to predict the actions of other persons by means of theorizations about what is going on in their minds, and these theorizations are acquired through social relationships. Fundamentally, it is on this premise that the tests are based. This type of theory of other minds rests on how we learn socially to relate possible enunciations with situations we have experienced together with other persons, and with our own possible mental states and those of others. For example, we master the use of sentences such as "I could help you with this task," not only with the aim of describing the fact that we are able to carry out a certain task, e.g., programming a computer, but also with the aim of making other persons think that we are really willing to carry out the task if we are required to do so. The use we make of a particular sentence and the implications that are part of the use of the sentence in certain contexts (these implications include what we are thinking about it) have a determined normative structure that is socially acquired. As Wittgenstein asserts, we learn socially, in determined contexts, to follow rules concerning the use of sentences that relate to our own psychological states and those of others. In Logic and Conversation (1967), Paul Grice ${ }^{7}$ further asserts that when we make certain enunciations in determined contexts (which are similar to each other), we do not only express information directly, but we also imply more than the information that can be understood directly from the enunciation itself. In this way, says Grice, we can understand irony, metaphor, hidden intentions, and so on.

The authors affirm that tests based on the individual domain of theories of mind (of one's own mind and those of other persons) cannot be used for diagnosis, but only to compare reactions in different people. This statement is acceptable up to a certain point; nevertheless, it seems possible, in principle, to assess reactions in relation to social behaviors that are considered as standard and are characteristic of how we act socially in general terms. I believe it is possible to develop criteria for the assessment of patients' answers to the tests that are absolute, not merely comparative.

The decision to translate and adapt these theory of mind tests into Brazilian Portuguese will not only bring benefits to the treatment of psychopathological symptoms, such as those of schizophrenia, but will also help think of possible ways to assuage the harmful effects of reduced social cognition. In addition, they will allow us to better understand psychopathologies and their effects on the social relationships of those who suffer from them. The tests are based on ordinary theories of mind, i.e., where the vocabulary used is that of common sense, and the final aim is to assist in the cure or reduction of symptoms of scientifically classified illnesses. Thus, the gap between common and scientific language referred to earlier will be manifested in the way the tests are used, and will have to be bridged by means of other theoretical devices.

In addition, the ways in which the results of the tests can be applied to the treatment of psychopathologies are restricted by the limits imposed by theoretical developments made over the last 30 years. Over this period, new approaches to the mind have been added to the more traditional analyses of the philosophy of language of the 20th century. Some of these approaches follow the tradition of Descartes, while other, more recent ones have their roots in neurological and cognitive sciences, and have added new neurophysiological (see Damásio ${ }^{8}$ ) and evolutionist knowledge to Wittgenstein's argument against the idea of a private language.

We can also add a number of other important recent views to the discussions concerning private language that followed Wittgenstein's later work and the pragmatic tradition of the philosophy of language, viz:

a. There is a preestablished harmony between human beings, in the sense that we are born with a predisposition to recognize significant features in what we perceive and to classify these features in determined ways (see Quine ${ }^{9}$ ).

b. There appear to be innate predispositions for the use of certain grammatical structures, such as subject and predicate (see Chomsky ${ }^{10}$ ).

c. Human beings and animals in general act in accordance with a kind of empathy that allows them to follow, to act together (see Tomasello ${ }^{11}$ ) with regard to different scenes and events, so that they can know what others are feeling or thinking.

d. We should abandon certain linguistic views of human knowledge held in the second half of the 
20th century, which asserted that knowledge is completely propositional (see Davidson, ${ }^{12}$ McDowell ${ }^{13}$ ), and focus on investigations into human perception, something that is often direct and not mediated by language (see Gibson ${ }^{14}$ ).

e. Notwithstanding research into artificial intelligence (AI), which presupposes a symmetry between human ways of thinking and computerized systems (see discussions between Searle ${ }^{15}$ and Putnam ${ }^{16}$ on the subject), we should change the focus of our investigations into human cognition to the interaction between brain, body, and environment (see Clark ${ }^{17}$ ), taking, if we want, linguistic mediation into account, but without giving special emphasis to this factor in our analysis of the interaction.

f. We should always stress the fact that human beings belong to an evolutionary drift in order to be able to explain predispositions and intentions in brainbody-environment interactions (see Maturana \& Varela, ${ }^{18}$ Clark $^{17}$ and Millikan $\left.{ }^{19}\right)$.

Thus, it is possible to foresee a new approach to the classic questions of the philosophy of mind, according to which the central focus will not be on an investigation into verbal behaviors, but rather into social behaviors, in which bodies that perceive and think participate; in this sense, we are all thinking social bodies. The idea that our minds are not, strictly speaking, individual is part of the reflection on how we use our bodies (how we incorporate cognition, see Varela et al. ${ }^{20}$ ), instruments, other bodies, other minds, and the environment in general to store information (i.e. we have extended minds, see Clark $\&$ Chalmers $^{21}$ ). Not all the information we have at our disposal in the world is stored in our brain.

I therefore believe that these new focuses on the mind will allow us to develop innovative approaches to tests, diagnosis, and treatment of psychopathologies, making it possible to add new findings to existing tests that follow classical views of the human mind. These new perspectives will stress the importance of joint perception and of the integration of our bodies with the social environment.

\section{Acknowledgments}

I wish to thank Flávio Kapczinski for his encouragement in getting me to consider more closely the links between my own investigations in the philosophy of language and still-unanswered questions in the field of experimental psychiatry.

\section{References}

1. Descartes R. Meditações. In: Civita V, editor. Os pensadores: Descartes. $3^{a}$ ed. São Paulo: Abril Cultural; 1983. (Translated by J. Guisburg and Bento Prado Júnior.)

2. Wittgenstein L. [1953]. Philosophische Untersuchungen. In: Wittgenstein L. Werkausgabe. Band I. Frankfurt am Main: Suhrkamp; 1990.

3. Ryle G. The concept of mind. Harmondsworth: Penguin Books; 1949.

4. Austin J. Outras mentes. In: Ryle G, Austin JL, Quine WVO, Strawson PF. Ensaios. São Paulo: Abril Cultural; 1980. p. 85-113.

5. Quine WVO. Epistemology naturalized. In: Quine WVO. Ontological relativity and other essays. New York: Columbia University; 1969. p. 69-90.

6. Sanvicente-Vieira BS, Brietzke E, Grassi-Oliveira R. Translation and adaptation of Theory of Mind Tasks into Brazilian Portuguese. Trends Psychiatry Psychother. 2012;34(4):178-85

7. Grice P. Studies in the way of words. Cambridge/London: Harvard University; 1989.

8. Damásio A. The feeling of what happens: body and emotion in the making of consciousness. Orlando: Harcourt; 1999.

9. Quine WVO. Natural kinds. In: Quine WVO. Ontological relativity and other essays. New York: Columbia University; 1969. p. 114-38.

10. Chomsky N. New horizons in the study of language and mind. Cambridge: Cambridge University; 2000.

11. Tomasello M. The cultural origins of human cognition. Cambridge: Harvard University; 1999.

12. Davidson D. Inquiries into truth and interpretation. 4th ed. Oxford: Clarendon; 1991.

13. McDowell J. [1994]. Mind and world. Cambridge/London: Harvard University; 1996.

14. Gibson JJ. The senses considered as perceptual systems. Westport: Greenwood; 1966.

15. Searle J. Intentionality: an essay in the philosophy of mind. Cambridge: Cambridge University; 1983.

16. Putnam H. Realism with a human face. Cambridge/London: Harvard University; 1990.

17. Clark A. Being there: putting brain, body, and world together again. Cambridge/London: MIT; 1997.

18. Maturana HR, Varela FJ. A árvore do conhecimento: as bases biológicas da compreensão humana. São Paulo: Palas Athena; 2001.

19. Millikan RG. Varieties of meaning: the 2002 Jean Nicod lectures. Cambridge: MIT; 2004.

20. Varela FJ, Thompson E, Rosch E. The embodied mind: cognitive science and human experience. Cambridge/ London: MIT; 1993.

21. Clark A, Chalmers D. The extended mind. Analysis. 1998;58:7-19. 